\title{
Semaphorin-1a Functions as a Guidance Receptor in the Drosophila Visual System
}

\author{
Patrick Cafferty, ${ }^{\star}$ Li Yu, ${ }^{\star}$ Hong Long, and Yong Rao \\ McGill Centre for Research in Neuroscience and Department of Neurology and Neurosurgery, McGill University Health Centre, Montreal, Quebec H3G 1A4, \\ Canada
}

The evolutionarily conserved Semaphorin family proteins are well known axon guidance ligands that mediate both attractive and repulsive responses in invertebrates and vertebrates. In this study, we show that the Drosophila Semaphorin-1a (Sema1a), a transmembrane Semaphorin, is required cell autonomously in adult photoreceptor (R-cell) axons for the establishment of an appropriate topographic termination pattern in the optic lobe. Loss of semala disrupts the association of neighboring R-cell growth cones leading to defects in local termination pattern, whereas overexpression of semala induces the hyper-fasciculation of R-cell axons. The function of Semala in R-cell axon guidance absolutely requires its cytoplasmic domain. We propose that Semala functions as a receptor in regulating $\mathrm{R}$-cell axon guidance in the Drosophila visual system.

Key words: Semaphorin-1a; axon guidance; axon guidance receptor; Drosophila visual system; neuronal connectivity; semaphorin

\section{Introduction}

The Semaphorin family proteins, including both secreted and membrane-associated forms, are well known axon guidance ligands (Pasterkamp and Kolodkin, 2003). In Drosophila, the transmembrane Semaphorin-1a (Semala) has been shown previously to mediate the defasciculation of motor axon bundles at specific choice points (Yu et al., 1998). Semala binds to its receptor Plexin A (PlexA) (Winberg et al., 1998), which in turn triggers downstream signaling events involving the receptor tyrosine kinase Otk (Winberg et al., 2001), the evolutionarily conserved flavoprotein monooxygenase molecule interacting with CasL (MICAL) (Terman et al., 2002), and the A kinase anchoring protein Nervy (Terman and Kolodkin, 2004), leading to a repulsive growth-cone response. Semala has also been shown to be involved in synaptic formation (Godenschwege et al., 2002). That overexpression of wild-type Semala, but not a truncated Semala mutant protein lacking the cytoplasmic domain, caused a gainof-function phenotype (Godenschwege et al., 2002), raises the interesting possibility that Semala functions as a receptor in synaptic formation. However, because the cytoplasmic-domaindeleted Semala mutant still rescued the semala loss-of-function synaptic formation phenotype (Godenschwege et al., 2002), it

\footnotetext{
Received Sept. 11, 2005; revised Jan. 6, 2006; accepted Feb. 7, 2006.

This work was supported by an operating grant (MOP-14688) awarded to Y. R. from Canadian Institutes of Health Research. We thank Don van Meyel for critical reading of this manuscript; the Bloomington Stock Center for fly stocks; Developmental Studies Hybridoma Bank at University of lowa for MAb 24B10; Corey Goodman for UASsema1a and UAS-Fas Il; Alex Kolodkin for sema 1a ${ }^{\text {P1 }}$, UAS-Nervy, Df(3R)swp2 ${ }^{\text {MICAL }}$, and anti-Sema1a antibody; and Rodney Murphey for sema1a ${ }^{\Delta \text { cyt }}$

*P.C. and L.Y. contributed equally to this work and are listed alphabetically.

Correspondence should be addressed to Yong Rao, Centre for Research in Neuroscience, The Montreal General Hospital Research Institute, Room L7-136, 1650 Cedar Avenue, Montreal, Quebec H3G 1A4, Canada. E-mail: yong.rao@mcgill.ca.

D0I:10.1523/JNEUROSCI.3845-05.2006

Copyright $\odot 2006$ Society for Neuroscience $\quad$ 0270-6474/06/263999-05\$15.00/0
}

remains unknown whether endogenous Semala truly functions as a receptor in the nervous system.

Our previous study implicates a role for Otk, a component of the PlexA receptor complex for Semala in mediating the defasciculation of embryonic motoneuron axons (Winberg et al., 2001), in layer-specific targeting of a subset of R-cell axons (i.e., R1-R6) in the adult visual system (Cafferty et al., 2004). The function of Otk in R-cell axons, however, appears to be independent of Semala because the R-cell projection pattern in semala null mutants was different from that in otk mutants (Cafferty et al., 2004). In this study, we show that Semala is required autonomously in R-cell axons for the establishment of appropriate topographic termination pattern in the optic lobe. The cytoplasmic domain of Semala is absolutely required for its function in $\mathrm{R}$-cell axons. These results are consistent with a role for Semala to act as a receptor to regulate $\mathrm{R}$-cell axon guidance.

\section{Materials and Methods}

Genetics. Semala and Fasciclin II (Fas II) were overexpressed in R-cell axons by crossing UAS-semala and UAS-Fas II flies with the GMR-GAL4 driver line, respectively. Transgene rescue was performed by crossing elav-GAL4 (C155); $D f(2) N 22-5 / B c$ flies with UAS-sema1a, sema ${ }^{\mathrm{P} 1} / B c$. The R-cell projection pattern in elav-GAL4 (C155)/+; UAS-semala, sema ${ }^{\mathrm{P} 1} / D f(2) N 22-5$ was compared with that in UAS-semala, sema ${ }^{\mathrm{P} 1} /$ $D f(2) N 22-5$ or elav-GAL4 (C155)/+; UAS-semala ${ }^{\Delta \mathrm{cyt}}$, sema ${ }^{\mathrm{P1}} /$ $D f(2) N 22-5$. To generate single semala mutant R-cell axons, $h s F L P$, UAS-mCD8::GFP, elav-GAL4 (C155); sema ${ }^{\mathrm{P} 1}$, FRT40A/+ flies were crossed with Tub-GAL80, FRT40A flies. The progeny were heat-shocked at $37^{\circ} \mathrm{C}$ for $1 \mathrm{~h}$ at larval stage to induce mitotic recombination. To completely remove the MICAL gene in R-cells overexpressing Semala, genetic crosses were performed to generate the larvae with the genotype: eyFLP; GMR-GAL4, UAS-sema1a/+; FRT82B, Df(3R)swp $2^{\mathrm{MICAL} /}$ FRT $82 B, w^{+} M(3) R p S 3^{2}$.

Histology and immunohistochemistry. Plastic sectioning of adult eyes was performed as described previously (Cafferty et al., 2004). Eye-brain complexes from third-instar larvae were dissected and stained as described pre- 
viously (Ruan et al., 1999). Monoclonal antibody (MAb) $24 \mathrm{~B} 10$ and anti- $\beta$-galactosidase antibodies were used at 1:200 and 1:1000 dilutions, respectively. The secondary antibodies (Jackson ImmunoResearch, West Grove, PA) were used at 1:200 dilution. Epifluorescent images were captured using a high-resolution fluorescence imaging system (Canberra Packard, Mississauga, Ontario, Canada) and analyzed by $2 \mathrm{D}$ Deconvolution using MetaMorph imaging software (Universal Imaging Corporation, Brandywine, PA). The severity of the R-cell hyperfasciculation phenotype was quantified by counting the number of R-cell axon bundles that were located between lamina and medulla.

\section{Results}

Semala is expressed in R-cell axons and growth cones

To determine whether semal a plays a role in $\mathrm{R}$-cell axon guidance, we examined whether Semala is expressed in R-cell axons at the third-instar larval stage when the adult Rcell-to-optic-lobe connection pattern begins to form. The distribution of Semala in the developing visual system was examined using an affinity-purified anti-Semala antibody. At the third-instar larval stage, precursor cells in the eye-imaginal disc begin to differentiate into R-cells that project axons through the optic stalk into the optic lobe. The R-cell projection pattern at this stage can be visualized by staining using MAb 24B10 (Fig. 1 A). Strong Semala staining was observed in R-cell bodies and their axons in the eye disc, the optic stalk, and the optic lobe (Fig. $1 B, C$ ). Within the lamina, the staining was present in R-cell axons as well as R1-R6 growth cones in the lamina plexus. Strong staining was also observed throughout the medulla neuropil comprising of R7 and R8 axons as well as non-R-cell axons. In sema $1 a^{\mathrm{P} 1}$ eye-specific mosaic individuals (Fig. $1 D-F$ ), the staining was missing in many regions of the eye disc, optic stalk, and optic lobe, confirming the specificity of anti-Semala antibody. We conclude that Semala is present in R-cell axons and their growth cones.

semala is specifically required for the establishment of an appropriate topographic termination pattern in the optic lobe We performed a detailed phenotypic analysis to determine the potential role of Semala in R-cell axon guidance. In wild type (Fig. 2A), the differentiating R-cells send out axons toward the posterior end of the eye disc where they converge and subsequently enter the optic stalk. After exiting the optic stalk, R-cell axons fan out to migrate over the superficial lamina. After reaching their appropriate topographic locations in between two layers of lamina glial cells (i.e., the intermediate target of R1-R6 axons), R1-R6 growth cones stop extension, expand significantly in size, and form close contacts with neighboring growth cones, resulting in the establishment of a continuous and dense terminal layer (Fig. 2A). During pupation, R1-R6 axons extend away from this region to seek appropriate lamina neurons for synaptic formation (Meinertzhagen and Hanson, 1993; Clandinin and Zipursky, 2002). R7 and R8 growth cones pass through the lamina into the medulla, where they also expand in size and elaborate a precise topographic termination pattern (Fig. $2 \mathrm{~A}$ ).

To examine the potential role for Semala in R-cell axon guidance, we examined R-cell projection pattern in semala mutants at third-instar larval stage before synaptic formation. In homozygous semala ${ }^{\mathrm{P} 1}$ mutant larvae (Fig. $2 \mathrm{~B}$ ), the initial outgrowth of $\mathrm{R}$-cell axons appeared normal. Mutant R-cell axons migrated correctly from the eye disc into the optic stalk, which was morphologically indistinguishable from that in wild type. After R-cell axons exited from the optic stalk en route to their termination region, however, severe defects were observed (Fig. 2B). R1-R6 growth cones failed to pack into a dense termination layer in all mutant hemispheres examined $(n=11)$. Instead, they scattered around the lamina terminal field and appeared to be unable to establish a close association in the target region. Some R1-R6 axons did not stop at their appropriate topographic termination region and instead migrated laterally into incorrect locations in the lamina (Fig. 2 B). Similar expressivity of phenotype were observed in semala ${ }^{\mathrm{P} 1}$ hemizygotes ( $n=30$ hemispheres), consistent with the null nature of this allele (Yu et al., 1998).

Although severe defects in R-cell axon termination pattern within lamina were observed in semala mutants, the laminaversus-medulla target selection appeared essentially normal. The majority of R2-R5 axons, a subset of R1-R6 axons labeled by the ro- $\tau$-lac $Z$ marker, still stop within the lamina layer in semala mutants $(n=15)$ (Fig. 2, compare $D, C)$. Consistent with the phenotype observed with MAb $24 \mathrm{~B} 10$ staining (Fig. 2B), we found that the organization of R2-R5 axons in the lamina plexus was disrupted in semala mutants (Fig. $2 D$ ).

To determine whether above defects were because of abnormal eye development, we examined R-cell differentiation and patterning in semala mutant eye disc and adult mosaic eye. Plastic sectioning of adult semal a mosaic eye did not reveal any defect in either the number or the organization of R-cells within each mutant ommatidium (0 of 996 mutant ommatidia examined) (Fig. 2, compare $F, E$ ). The gross organization of mutant ommatidia in each clone also appeared normal. No defects in either the differentiation or the organization of R-cell clusters were observed in third-instar larval eye discs in semala mutants (data not shown). These data exclude the possibility that the R-cell axon guidance phenotype in semala mutants is secondary to abnormal R-cell development in the eye.

\section{sema1a is required cell-autonomously in R-cells for} axonal projections

To determine whether above defects reflect a role for semala in R-cells, we examined the projection pattern of semal a mutant R-cell 

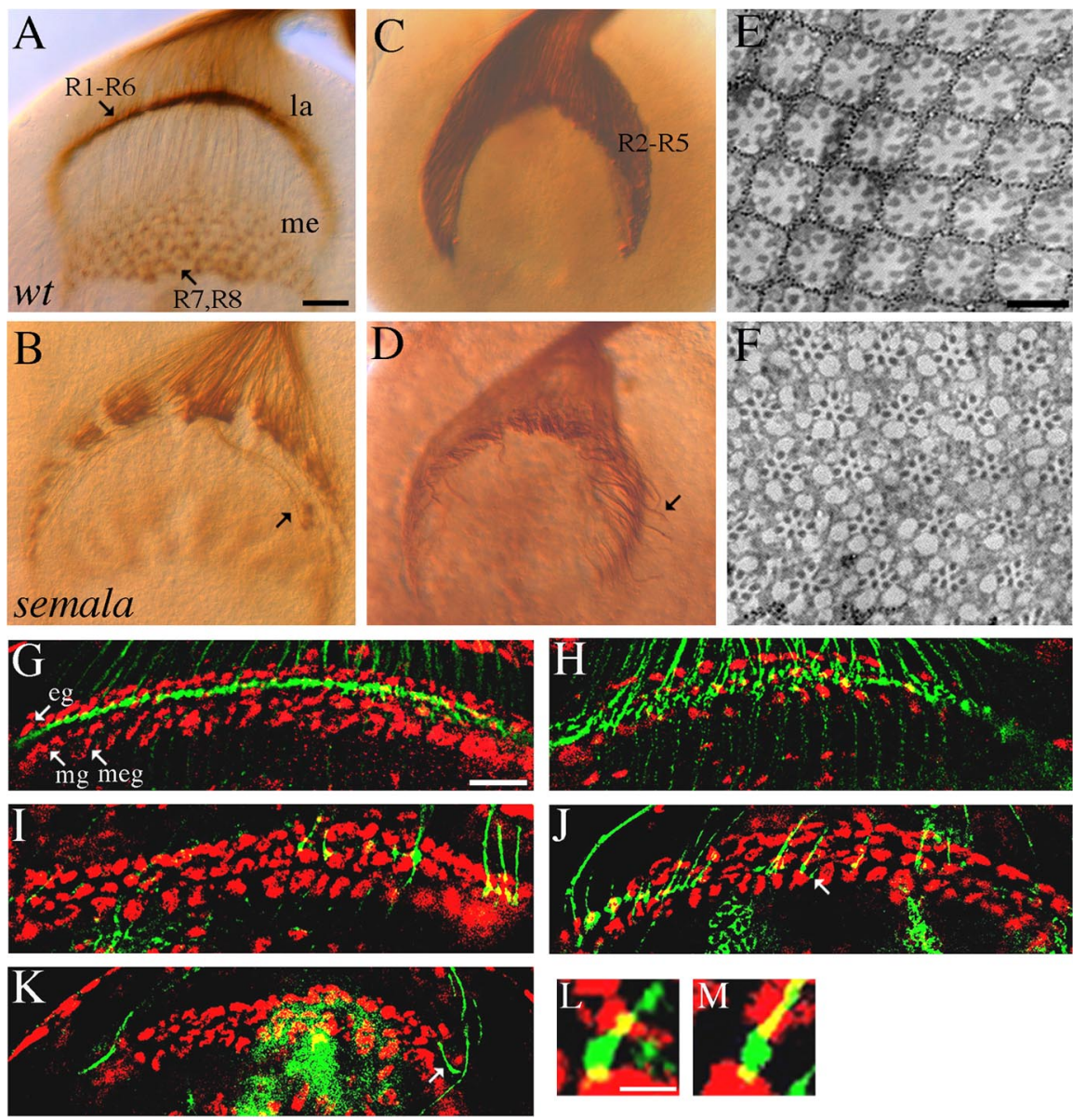

Figure 2. semala is specifically required for the establishment of an appropriate local retinotopictermination pattern. $A, B$, Third-instar larval eye-brain complexes were stained with MAb24B10 to visualize all R-cell axons. In wild type (wt; $A$ ), expanded R1-R6 growth cones associate closely with each other and elaborate a smooth and dense terminal layer in the lamina (la). R7 and R8 axons project through the lamina into the medulla (me). In a sema $1 a^{\mathrm{P} 1}$ homozygote $(\boldsymbol{B}), \mathrm{R} 1-\mathrm{R} 6$ growth cones associated loosely with neighboring growth cones. Some R1-R6 axons migrated laterally at the bottom of lamina into incorrect topographic locations ( $\boldsymbol{B}$, arrow). $\boldsymbol{C}, \boldsymbol{D}, \mathrm{R} 2-\mathrm{R} 5$ axons in wild type $(\boldsymbol{C})$ and sema $1 a^{\mathrm{P} 1}$ homozygous mutants $(\boldsymbol{D})$ were labeled with the ro- $\tau$-lacZ marker. Like that in wild type $(\boldsymbol{C})$, the vast majority of mutant R2-R5 axons still terminated in the lamina (D). Note that some R2-R5 axons (arrow) migrated abnormally at the bottom of lamina (D). $\boldsymbol{E}, \boldsymbol{F}$, Wild-type $(\boldsymbol{E})$ and sema $1 a^{\mathrm{P} 1}$ mosaic $(\boldsymbol{F})$ adult eyes were embedded in Epon and sectioned. $\boldsymbol{G}, \boldsymbol{H}, \mathrm{R}$-cell axons (green) and glial nuclei (red) in wild-type $(\boldsymbol{G})$ and sema1a ${ }^{\mathrm{P} 1}$ mosaic $(\boldsymbol{H})$ third-instar larval brains were double-stained with MAb $24 B 10$ and anti-Repo, respectively. In wild type $(\boldsymbol{G}), \mathrm{R} 1-\mathrm{R} 6$ growth cones terminate in between epithelial $(\mathrm{eg})$ and marginal $(\mathrm{mg})$ glial layers. In a sema1a ${ }^{\mathrm{P} 1}$ mosaic individual $(\boldsymbol{H})$ in which large clones of homozygous mutant eye tissues were generated (Newsome et al., 2000), R1-R6 growth cones were distributed in a much broader area between the lamina glial and the medulla glial cells (meg). $\boldsymbol{I}-\boldsymbol{K}$, Single wild-type $(\boldsymbol{I})$ or sema1a mutant $(\boldsymbol{J}, \boldsymbol{K})$ axons were positively labeled. sema 1a single-mutant axons frequently passed over the marginal glial layer $(\boldsymbol{J}$, arrow). Note the three-layered glial structure at the edge of lamina termination site was distorted as a result of mounting. Axons at these regions were not included when the phenotype of stopping at incorrect glial layers was quantitated. Some $(\boldsymbol{K}$, arrow) terminated at incorrect topographic locations. $\boldsymbol{L}, \boldsymbol{M}$, High-resolution view of expanded wild-type $(\boldsymbol{L})$ and sema $1 a^{\mathrm{P} 1}$ mutant $(\boldsymbol{M})$ R-cell growth cones (green) surrounded by glial cells (red) at lamina termination site. Scale bars: (in $\boldsymbol{A}) \boldsymbol{A}-\boldsymbol{D}, 20 \mu \mathrm{m}$; (in $\boldsymbol{E}$ ) $\boldsymbol{E}, \boldsymbol{F}, 10 \mu \mathrm{m}$; (in $\boldsymbol{G}$ ) $\mathbf{G}-\boldsymbol{K}, 20 \mathrm{~mm}$; (in L) $L, M, 4 \mu \mathrm{m}$.

axons in an otherwise heterozygous or wild-type target region by using genetic mosaic analysis. In wild type, R1-R6 axons stop at their lamina intermediate target region in between two layers of glial cells (i.e., epithelial and marginal glia) (Fig. 2G). When large patches ( $>90 \%$ eye tissues) of semala mutant R-cells were generated by eye-specific mitotic recombination (Newsome et al., 2000), although the organization of glial cells in the lamina remained normal, R1-R6 axon termination pattern was disrupted (Fig. $2 H$ ). Many R1-R6 growth cones failed to stop at correct locations after reaching their intermediate target. This result indicates that semala is required in R-cells for correct axon termination.

To determine whether Semala is required in a cell-autonomous or non-cell-autonomous manner, we examined the projection of single mutant axons using the mosaic analysis with a repressible marker method (Lee and Luo, 1999). Single sema1a mutant cell mosaics in the eye were generated by expressing the FLP recombinase under the control of heat-inducible promoter at larval stage. In control (wild-type single mosaics), the vast majority ( 57 of 58 labeled single axons) of R1-R6 axons terminated normally (Fig. 2I). In contrast, many labeled single sema1a mutant R1-R6 axons $(\sim 63 \% ; n=$ 89) failed to stop at correct locations (Fig. $2 J$ ). Some mutant axons moved away from appropriate topographic locations and extended laterally within the lamina $(\sim 10 \%$; $n=89$ ) (Fig. $2 K$ ), whereas in wild-type control, most labeled single axons stopped at correct topographic locations (57 of 58 labeled single R1-R6 axons). Like that in wild type (56 of 58 single R1-R6 axons) (Fig. 2L), R-cell growth cones still expanded normally in the lamina in semala mutants (87 of 89 single mutant axons) (Fig. $2 M$ ). These results indicate a cell autonomous role for Semala in R-cell axon guidance.

\section{Overexpression of semala induced the} hyper-fasciculation of R-cell axons That R1-R6 growth cones failed to establish a highly condensed R1-R6 terminal layer in semala mutants raised the possibility that Semala is involved in promoting the local interaction between R1-R6 growth cones at their intermediate target region. To further address this possibility, we examined whether overexpression of Semala in R-cell axons would increase the association of R-cell axons.

Semala was overexpressed in R-cell axons by using the eye-specific GMR-GAL4 driver. When the GMR-GAL4 driver was used to overexpress Fas II, a well known homophilic cell adhesion molecule required for axonal fasciculation (Lin et al., 1994), we observed an axonal hyper-fasciculation phenotype (Fig. 3B; supplementary Table 1, available at www.jneurosci.org as supplemental material). If Semala, like Fas II, promotes $\mathrm{R}$-cell axon interactions, one would predict that overexpression of Semala should produce a similar hyper-fasciculation phenotype. Overexpression of Semala was confirmed by staining R-cells with anti-Semala antibody (data not shown). Indeed, we found that overexpression of Semala caused a hyper-fasciculation phenotype similar to that in larvae overexpressing Fas II (Fig. 3, compare $C, B$; supplementary Table 1, available at www.jneurosci.org as supplemental material). Thicker axon bundles were formed in both lamina and medulla in all hemispheres examined $(n=50)$, coincident with the presence of large clumps of terminals in the lamina plexus. This phenotype is dosage dependant because an increase in the dosage of the semala transgene dramatically enhanced the phenotype $(100 \% ; n=35)$ (Fig. 3D; supplementary Table 1, available at www.jneurosci.org as supplemental material). When both Semala and Fas II were overex- 

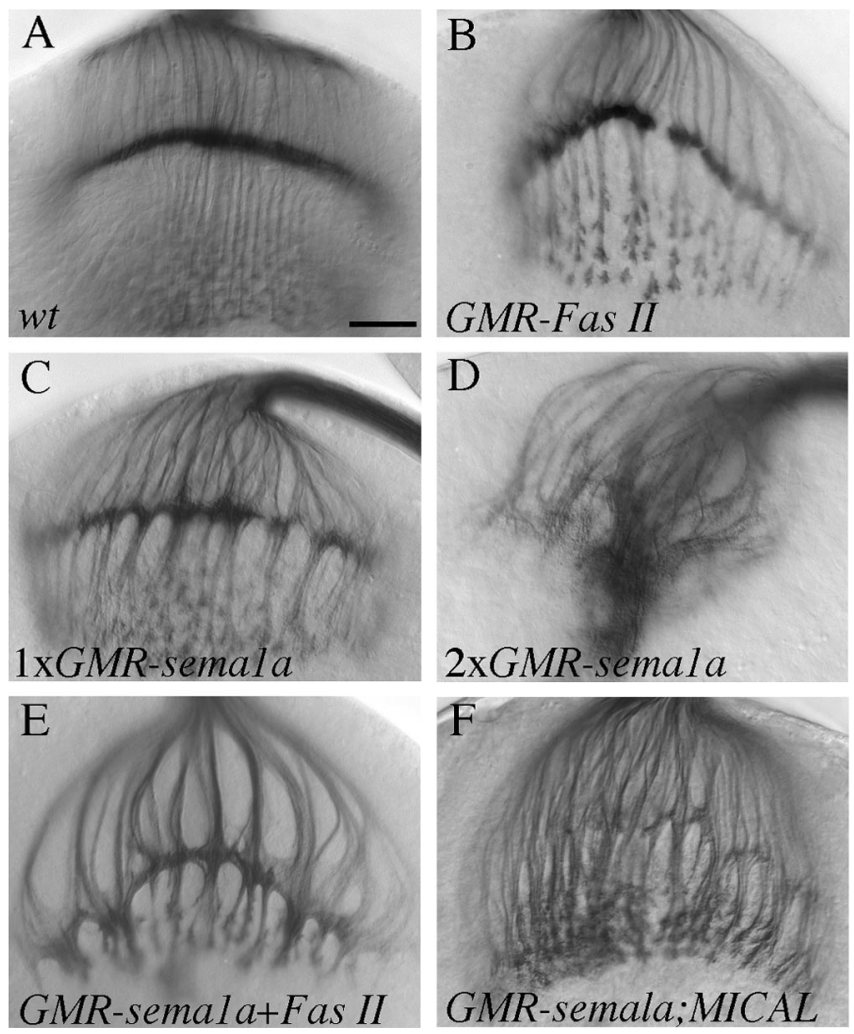

Figure 3. Overexpression of Sema1a induced the hyper-fasciculation of R-cell axons. $A$, Wild type (wt). $\boldsymbol{B}$, Overexpression of Fas Il in R-cell axons induced the formation of thicker bundles. $\boldsymbol{C}$, Overexpression of Sema1a also caused a hyper-fasciculation phenotype. In larvae carrying two copies of the UAS-sema1a transgene (D), the phenotype becomes much more severe. R-cell axons form large clumps in the lamina and appeared to be unable to defasciculate and extend deeply into the medulla. In larvae carrying one copy of UAS-Fas II and UAS-sema1a (E), the phenotype is much stronger than that in larvae carrying a single copy of UAS-Fas II $(\boldsymbol{B})$ or UAS-sema 1a $(\boldsymbol{C})$. The complete loss of the MICAL gene $(\boldsymbol{F})$ did not suppress the Sema1a overexpression phenotype. Scale bar: (in $\boldsymbol{A}) 20 \mu \mathrm{m}$.

pressed in R-cell axons, the hyper-fasciculation phenotype was dramatically enhanced (Fig. 3E; supplementary Table 1, available at www.jneurosci.org as supplemental material). This result is in marked contrast to the previous observation that semala counters the attractive action of Fas II in embryonic motor axons (Yu et al., 2000) and is consistent with a role for Semala to promote R-cell axon interactions.

Semala has been shown to bind to its receptor PlexA to mediate repulsive interactions between motor axons (Winberg et al., 1998). To determine whether the above Semala-induced R-cell hyper-fasciculation phenotype is also dependent on the activation of the PlexA signaling pathway, we examined the potential epistatic interaction between semala and genes in the PlexA pathway. We found that the complete loss of the MICAL gene, which functions downstream of PlexA in both invertebrates and vertebrates (Terman et al., 2002), did not modify the semala overexpression phenotype $(n=19)$ (Fig. $3 F$; supplementary Table 1 , available at www.jneurosci.org as supplemental material).

To further determine whether the classical PlexA signaling pathway plays a role in R-cell axon termination, we examined whether interfering with the PlexA signaling pathway would cause a semala-like phenotype. However, we found that R-cell axon termination pattern remained essentially normal in the absence of MICAL (supplementary Fig. 1C, available at www. jneurosci.org as supplemental material). The effect of interfering with PlexA signaling was also examined by overexpressing the Nervy gene encoding for a member of A kinase anchoring proteins (Terman and Kolodkin, 2004). Overexpression of Nervy in embryonic motor axons could effectively antagonize the PlexA signaling, causing a guidance phenotype identical to loss of PlexA or semala (Terman and Kolodkin, 2004). However, no obvious defect was observed when Nervy was overexpressed in R-cell axons (supplementary Fig. $1 D$, available at www.jneurosci.org as supplemental material) or glial cells in the optic lobe (supplementary Fig. $1 E$, available at www.jneurosci.org as supplemental material). These results suggest that the function of Semala in R-cell axons is independent of the classical PlexA signaling pathway.

\section{The cytoplasmic domain of Semala is indispensable for its action in R-cell axon guidance}

The above analyses support a specific role for Semala in R-cell axons. Semala may function as a ligand that activates its receptor on neighboring R-cell growth cones to promote their association. Alternatively, because Semala contains a cytoplasmic domain, it may function as a guidance receptor to mediate the interactions between R-cell axons, which is supported by that semala is required autonomously in single R1-R6 axons (Fig. 2). To address this, we examined whether the cytoplasmic domain of Semala is required for its action in $\mathrm{R}$-cell axon guidance.

First, we tested whether deleting the cytoplasmic domain of Semala affects its ability to induce the hyper-fasciculation phenotype. The semala ${ }^{\Delta \text { cyt }}$ transgene encoding a membrane-associated Semala mutant protein in which the C-terminal amino-acid sequence 695-899 of the cytoplasmic domain (amino acids 680-899) is deleted (Godenschwege et al., 2002) was overexpressed in R-cell axons. Surprisingly, we found that overexpression of sema $1 a^{\Delta \text { cyt }}$ was unable to induce the hyper-fasciculation of R-cell axons ( 0 of 23 hemispheres) (Fig. 4B; supplementary Table 1, available at www. jneurosci.org as supplemental material), but instead caused a phenotype indistinguishable from that in semala mutants $(\sim 80 \%$; $n=23$ ) (compare Figs. $4 B, 2 B$ ). This result indicates that semal $a^{\Delta \text { cyt }}$ acts as a dominant-negative form to interfere with the function of endogenous Semala.

We then tested whether the cytoplasmic domain is required for rescuing the semala phenotype. We chose the neuronal-specific driver elav-GAL4 for the rescue experiment. The expression of wildtype sema1 a under control of this driver in wild-type larvae caused a weaker hyper-fasciculation phenotype (supplementary Fig. 2C, available at www.jneurosci.org as supplemental material), whereas no defect was observed when semala $a^{\Delta \text { cyt }}$ was expressed under control of elav-GAL4 in wild-type larvae (supplementary Fig. 2 , available at www.jneurosci.org as supplemental material). Neuronalspecific expression of wild-type semala substantially rescued the phenotype in semala mutants (14 of 22 mutant hemispheres) (Fig. $4 C)$. In contrast, all mutant hemispheres expressing sema1 $a^{\Delta \text { cyt }}$ still displayed the semala phenotype $(n=15)$ (compare Figs. $4 D, 2 B)$, indicating that the cytoplasmic domain is essential for the function of Semala in R-cell axons. This data, together with that overexpression of semal $a^{\Delta \text { cyt }}$ under control of GMR-GAL4 in wild-type larvae caused a semala-like loss-of-function phenotype (see above), suggests strongly that Semala functions as a receptor in R-cell axons.

\section{Discussion}

Semaphorin family members have been studied extensively for their role as axon guidance ligands in both invertebrates and vertebrates. Godenschwege et al. (2002) demonstrated previously that the cytoplasmic domain of Semala, the Drosophila transmembrane Semaphorin, is required for inducing a gain-of-function synaptic forma- 
A
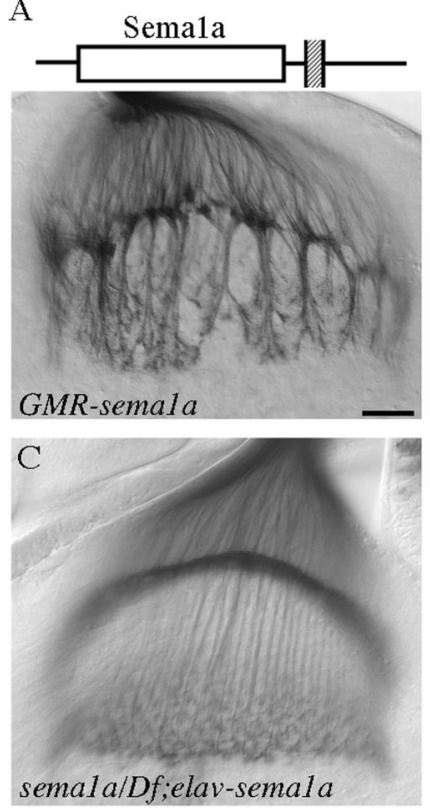

Figure 4. The cytoplasmic domain of Sema 1a is required for its function in R-cell axon guidance. $A$, Overexpression of wild-type Sema1a under control of GMR-GAL4 caused the hyper-fasciculation of R-cell axons. B, Overexpression of sema $1 a^{\Delta \text { cyt }}$ driven by GMR-GAL4 did not induce the formation of thicker bundles, but instead disrupted the organization of R1-R6 growth cones in the lamina plexus, which was indistinguishable from that in sema $1 a^{\mathrm{P} 1}$ mutants (Fig. 2B). C, Neuronal-specific expression of wild-type Sema1a under control of elav-GAL4 in a sema1a ${ }^{\mathrm{P} 1}$ hemizygote (i.e., sema1a ${ }^{\mathrm{P1}} /$ Df(2)N22-5) restored the normal R-cell projection pattern in 14 of 22 mutant hemispheres. The remaining eight mutant hemispheres displayed the axonal hyper-fasciculation phenotype (data not shown), likely caused by an above threshold expression level of the sema 1 a transgene in these individuals. $\boldsymbol{D}$, No rescue was observed when the sema $1 a^{\Delta \text { cyt }}$ transgene was expressed in a sema $1 a^{P 1}$ hemizygote. Note the discontinuous lamina plexus and the aberrant projections of some R-cell axons (arrow) at the bottom of lamina. Scale bar: (in A) $20 \mu \mathrm{m}$.

tion phenotype, raising the possibility that Semala functions as a receptor in synaptic formation. In this study, we provide several lines of evidence to support that Semala functions as a receptor in R-cell axons to regulate the formation of appropriate termination pattern in the optic lobe. First, we show that semala is required autonomously in single R-cell axons. Second, unlike overexpression of wildtype Semala, overexpression of the membrane-bound Semala ${ }^{\Delta c y t}$ mutant lacking the cytoplasmic domain is incapable of inducing a R-cell hyper-fasciculation phenotype. Third, the cytoplasmic domain of Semala is required for rescuing the semala loss-of-function phenotype. And finally, the Semala ${ }^{\Delta \text { cyt }}$ mutant lacking the cytoplasmic domain causes a dominant-negative effect when overexpressed in wild-type flies.

Semala may function as a guidance receptor in R1-R6 axons to promote the local interaction between neighboring growth cones when they reach their intermediate target region at the third-instar larval stage. The local interaction between R1-R6 growth cones has been shown to provide certain guidance information for R1-R6 axons to select their appropriate synaptic partners during pupation (Clandinin and Zipursky, 2000). Similarly, we speculate that a Semala-dependent interaction at third-instar larval stage may allow neighboring growth cones to communicate with each other, thus facilitating the formation of an appropriate retinotopic termination pattern in the lamina. An alternative model for the action of Semala is that Semala functions as a receptor in R1-R6 axons to mediate their interaction with cells in the lamina. Our current data does not allow us to distinguish among these possibilities. Although our data suggests strongly that Semala functions as a receptor in R-cell axons, the elucidation of the exact mechanism of Semala action awaits the identification of its upstream and downstream partners in the fly visual system.

It appears highly likely that transmembrane Semaphorins in vertebrates can also function as axon guidance receptors in the nervous system. Several vertebrate Semaphorins have been shown to be able to bind via their cytoplasmic domains to intracellular signaling proteins such as enabled/vasodilator-stimulated phosphoprotein-like protein (Klostermann et al., 2000) and c-Src (Eckhardt et al., 1997). While we were preparing this manuscript, Toyofuku et al. (2004) provided evidence to support that the chick transmembrane Semaphorin Sema6D can function as a receptor in cell migration during embryonic development. It will be of interest to determine whether these vertebrate transmembrane Semaphorins also function as axon guidance receptors in the nervous system.

\section{References}

Cafferty P, Yu L, Rao Y (2004) The receptor tyrosine kinase Off-track is required for layer-specific neuronal connectivity in Drosophila. Development 131:5287-5295.

Clandinin TR, Zipursky SL (2000) Afferent growth cone interactions control synaptic specificity in the Drosophila visual system. Neuron 28:427-436.

Clandinin TR, Zipursky SL (2002) Making connections in the fly visual system. Neuron 35:827-841.

Eckhardt F, Behar O, Calautti E, Yonezawa K, Nishimoto I, Fishman MC (1997) A novel transmembrane semaphorin can bind c-src. Mol Cell Neurosci 9:409-419.

Godenschwege TA, Hu H, Shan-Crofts X, Goodman CS, Murphey RK (2002) Bi-directional signaling by Semaphorin 1a during central synapse formation in Drosophila. Nat Neurosci 5:1294-1301.

Klostermann A, Lutz B, Gertler F, Behl C (2000) The orthologous human and murine semaphorin $6 \mathrm{~A}-1$ proteins (SEMA6A-1/Sema6A-1) bind to the enabled/vasodilator-stimulated phosphoprotein-like protein (EVL) via a novel carboxyl-terminal zyxin-like domain. J Biol Chem 275:39647-39653.

Lee T, Luo L (1999) Mosaic analysis with a repressible cell marker for studies of gene function in neuronal morphogenesis. Neuron 22:451-461.

Lin DM, Fetter RD, Kopczynski C, Grenningloh G, Goodman CS (1994) Genetic analysis of Fasciclin II in Drosophila: defasciculation, refasciculation, and altered fasciculation. Neuron 13:1055-1069.

Meinertzhagen IA, Hanson TE (1993) The development of the optic lobe. In: The development of Drosophila melanogaster (Bate M, Martinez-Arias A, eds), pp 1363-1491. Cold Spring Harbor, NY: Cold Spring Harbor.

Newsome TP, Asling B, Dickson BJ (2000) Analysis of Drosophila photoreceptor axon guidance in eye-specific mosaics. Development 127:851-860.

Pasterkamp RJ, Kolodkin AL (2003) Semaphorin junction: making tracks toward neural connectivity. Curr Opin Neurobiol 13:79-89.

Ruan W, Pang P, Rao Y (1999) The SH2/SH3 adaptor protein dock interacts with the Ste20-like kinase misshapen in controlling growth cone motility. Neuron 24:595-605.

Terman JR, Kolodkin AL (2004) Nervy links protein kinase a to plexinmediated semaphorin repulsion. Science 303:1204-1207.

Terman JR, Mao T, Pasterkamp RJ, Yu HH, Kolodkin AL (2002) MICALs, a family of conserved flavoprotein oxidoreductases, function in plexinmediated axonal repulsion. Cell 109:887-900.

Toyofuku T, Zhang H, Kumanogoh A, Takegahara N, Yabuki M, Harada K, Hori M, Kikutani H (2004) Guidance of myocardial patterning in cardiac development by Sema6D reverse signalling. Nat Cell Biol 6:1204-1211.

Winberg ML, Noordermeer JN, Tamagnone L, Comoglio PM, Spriggs MK, Tessier-Lavigne M, Goodman CS (1998) Plexin A is a neuronal semaphorin receptor that controls axon guidance. Cell 95:903-916.

Winberg ML, Tamagnone L, Bai J, Comoglio PM, Montell D, Goodman CS (2001) The transmembrane protein Off-track associates with Plexins and functions downstream of Semaphorin signaling during axon guidance. Neuron 32:53-62.

Yu HH, Araj HH, Ralls SA, Kolodkin AL (1998) The transmembrane Semaphorin Sema I is required in Drosophila for embryonic motor and CNS axon guidance. Neuron 20:207-220.

Yu HH, Huang AS, Kolodkin AL (2000) Semaphorin-1a acts in concert with the cell adhesion molecules fasciclin II and connectin to regulate axon fasciculation in Drosophila. Genetics 156:723-731. 